\title{
Teaching Pedagogies Used in Higher Education for Better Learning Outcomes
}

\author{
Goldie Gabrani ${ }^{1}$, Andrew Solomon ${ }^{2}$, Utkarsh Dviwedi ${ }^{3}$ \\ ${ }^{1}$ Professor, SOET, BML Munjal University, Gurgaon \\ ${ }^{2,3}$ B.Tech Student, SOET, BML Munjal University, Gurgaon \\ ${ }^{1}$ goldie.gabrani@bml.edu.in \\ 2andrew.solomon.14cse@bml.edu.in
}

This paper is aimed to exhibit some of the contemporary practices being implemented in the teaching methodology to make the learning experience better. Various innovative methodologies that have been implemented are discussed. The effect of implementing these ideologies on both teaching and learning experiences alike without the general gloomy perception of a classroom is studied.

Keywords: Joy of Engineering, Teaching Pedagogy, Innovation, Hands on Learning, How Stuff Works, Do It Yourself.

\section{Introduction}

Innovation as a concept has become huge and is not limited to any specific boundaries. With rapidly upgrading technologies, as newer becomes better it is critical for the old to be updated or replaced. A teacher is expected to know his subject and to do so, it is imperative for the teacher to constantly update $\mathrm{him} /$ herself to make certain that the student is kept up to date with what he/she is being taught. For this the teacher must him/herself become a student and familiarise him/herself, knowledge not only in their own subject but all other related fields. With a globalisation effect, the world of education too, hasshrunk. The teaching pedagogies have not seen as much innovation over the years as innovation has been seen in other fields like engineering.Yet, educationists are now focusing and beginning to research on newer teaching practices, for optimised learning outcomes [1]. The teaching process has a 
direct impact to the learning and absorbing mechanism of each student. However, each student has a different learning style through which they acquire knowledgeeffectively with optimum learning [4][5] as shown in Fig.1. By targeting students with individual learning styles and by categorizing them based on their approach, certain teaching pedagogies can be implemented to generalise discrete styles for a better outcome.The contents of this paper have been classified in a course wise manner, giving the various teaching pedagogies implemented in each course, also showcasing how each methodology used is different for different courses. BML Munjal University being a new university(only 3 semesters old) has a more optimistic approach to experimenting with newer and more innovative teaching styles and methods.

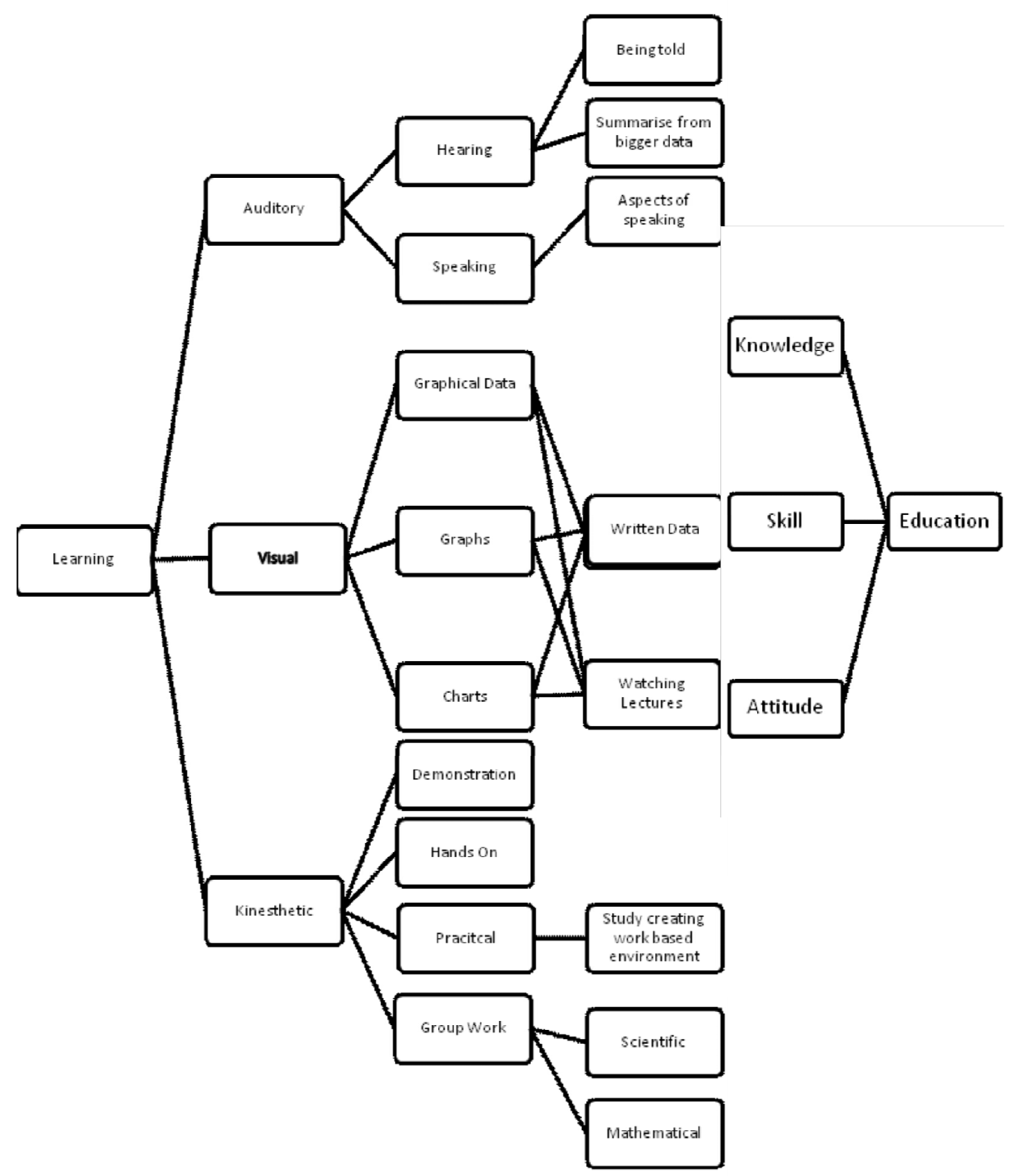

Fig.1. Different Learning Styles with an Educational Outcome [4] [5] 
This paper focuses on live examples of applied teaching methodologies which have been implemented at BML Munjal University, out of which there have been attempts with both successes and learnings. The paper discusses some of these practices and tries to explain the possible reasons for challenges and successes of implementation of each of the methods used. With innovative courses like Joy of Engineering, Emerging Life Sciences [2] and traditional courses like Computer Programming, Biology and Mathematics, the teaching learning idea has changed with respect to the students mind on how teaching goes on. It is shown for the different ideas to be adopted and a system be devised with flexibility to meet increased productivity as well as optimise teaching pedagogies so as to give a maximum learning output. This paper also links different learning styles with various teaching pedagogies.

\section{Innovation by Innovating - Joy of Engineering}

One of the main learning objectives of a student is to gain maximum knowledge, keeping in mind grades as an educational requirement as well. Often the idea of being graded turns out to oppose the whole idea of learning.Examinations and assignments are aimed at testing the knowledge of the student, but have continuously failed to be implemented with a learning outcome, rather than learning in itself. Based on the core of engineering, i.e. design, a course like Joy of Engineering[5], which is focused on implementing knowledge and giving the student a perception of what engineering is. The entire course is designed to be different from a lecture class. Each student gets a fair chance as the course is designed to promote auditory, visual and kinaesthetic learning (Fig.1).

Joy of Engineering is a course taken by all engineering students in the first semester itself. From the very beginning, students are divided in groups of 5 in a class of 60 and given assignments in the form of group activities. The studentsare made to work on ideas that interesteach group member; it gives each student a head start so that they can work on something that they like and find of common interest. This automatically makes the student a lot more confident about the whole course. The regular assignments from a normal lecture are converted to peer evaluated presentationsthat would be related to the weekly progress of the project[1] [5]. New ideas are encouraged and failure is welcome, given that there is learning. The idea behind presentations is to give a better insight to other teams of how the team is working and also what amends can be made by learning form others. It also gives the team a firm confirmation of what they are working on. The idea of presentations by each group takes teaching and learning to a different level altogether, where the student starts from scratch and as the team gains more knowledge on a topic, it is implemented as aproject. It has double benefit in terms of outcome - learning by doing as well as by demonstrating. The peer evaluation has its own pros and cons especially when students are new to this concept, as at times hard to judge-'who deserves what' based on little that one knew on how to judge.

Even with limited resources available, as each project was funded by each team itself, the learning experiences were advantageous as the intended outcome for project, was to experience real life based situation. The students learnt how to optimise solution with cutting costs at the same time. With the faculty as an overseer of the entire project and students going with the project as a team, there is always a check on the work of each project. Each team has the liberty of taking help from not only the faculty but other faculty related to the subject. Joy of Engineering is truly an innovation from the generic classroom where the classic classroom in changed into a hybrid workspace.

\section{Learning by Teaching - Emerging Life Sciences}

Many people opt for engineering because they are not very comfortable with biology. The students were astounded when they first got to know about the course being a part of their curriculum. As engineering students, anything related to biology may sound very unlikely. But as the students began with classes, they soon saw the impact of biology and biotechnology as an engineering term rather than related to pure biological sciences.

With upgradation of academic courses and the narrowing gap between various disciplinary courses, each course becomes an innovation of its own as it is introduced to a program course that it may not conventionally be a part of. Emerging life sciences is more, theoretical rather than practical and hands on based. Compared to engineering courses, given the innovative practical and hands on based knowledge that can be combined with teaching, it is rather hard to innovate in subject such as this.

However, in this course too, a model was 
implemented where students were divided in different groups and each group allotted a specific topic related to the subject. Each group was then assigned to prepare the topic as a lecture presentation. This was presented to the entire class where they used audio visual aid to explain topics. The rest of the class was allowed to question the group presenting regarding any doubts. Based on the knowledge of what they have prepared, the group presenting was required to make sure the students have their doubts cleared. This in turn had more than one teaching and learning outcome. The group presenting implements a learning by teaching sort of model whereas it became easier for the rest of the class to be more open to the teacher, in this case their own peer; and this makes the teaching learning process more interactive. The teacher on the other hand can easily grade the students as well as point out the common mistakes that the students may tend to make while perceiving a topic.

Apart from class presentations, each group was also given a semester longproject limited by only the knowledge and creativity of the students where they were to have an innovative approach to any field relating to keywords that include biology, technology, engineering and related terms. Being a semester long project, each team is expected to have come close to learning a lot about all relating terms to their project. With a project based approach, it would make learning a better experience alongside rethinking the whole concept of biology as a more innovative rather than a bookish course.

\section{Keeping up with the world - Mobile App Development}

It doesn't take time for newer technologies to come up and replace the old. Mobile app development has come up very recently. With an open source platform like android, it becomes very easy for anyone with minimal knowledge and a will to learn to develop and showcase his app on a global scale. This in itself is a promotion of knowledge and self-learning as well as implementing the ideas as one gets them. Mobile app development has been implemented at the university in collaboration with IBM. Withthe tie up with IBM as a partner, the university has tried an innovative way of implementing hands on learning by bringing the industry on campus for the students to gain more experience on the current technologies, with the ease of enjoying the experience in the classroom. It is a relatively unorthodox approach for such a course, being taught as early as 3rd semester of computer science engineering. Implementing the hands on approach with the basic engineering principles of design and optimization to make one's own app stand out and be more innovative. With no set down guidelines for the learning and course curriculum, the course aims for the students not to study, but to learn.

It is very different from the traditional courses. One cannot apply the same approach to study this subject as done with more theoretical subjects. The course is a dynamic course, constantly changing with as the world of Mobile apps upgrades. With minimal approach on theory and the code, more importance is given to the algorithms and problem solving. The student is made to think on every detail with the ease of moving forward without the details he/she is not comfortable with. This also will help in extend the students pre-requisite knowledge about $\mathrm{C} / \mathrm{C}++$ and would be helpful in the future with courses like Java and other programming languages. Instead of questioning the teacher on where the programming languages would help the student later, the students get to implement the languages they do not completely understand, which in turn will motivate them to learn more about the language to implement their ideas from their mind, on paper to code and finally an app.With all of these in mind, Mobile App Development, would play an important role in shaping the students as budding engineers with the motive of keeping them motivated.

\section{Interest Based Learning - Mathematics}

The mathematics faculty went with a very creative approach with the challenging assignments. Challenging assignments were aimed at pushing the limits of the students' knowledge and implementation of mathematical knowledge as well as brushing up their skills. With many interesting projects like, to find the equation of trajectory of every bird in the Rovio game ANGRY BIRDS and also mathematically model their special powers. Students felt an urge of curiosity and also a little pride in being engineering students and being able to use the 'less interesting' topics practically to the interests of all with promoting more visual and telekinetic learning

In the semester where complex numbers are taught, students were made to program a GUI which could transform a plane sheet representation of a map into a globe. This was truly an amazing experience as it tested or skills of visualization and with the help of computing, it became very easy to implement our 
knowledge. Combining the knowledge of one course in the other showed how two different courses are necessary for one to be an engineer and was a small glance of how the courses coming later would add to the knowledge and benefit us as engineering students. It could accurately track and tell us where the image of a point on a flat map would appear on a globular model. In the course Linear Algebra, students were given a choice between varieties of projects. Ranging from creating an encryption decryption program to study Google's page ranking algorithm, make a program on it creating a $25 * 25$ magic square and to study a GPS System. Such innovative projects create a natural interest in the subject to be studied upon.

\section{Flipping the Class - Physics}

No student likes to take home the burden of post class assignments and problems. The course of physics tested a flip classroom model. Lecture videos would be sent to the student to watch after the class timing. With the ease of being able to pause, play or rewind the lecture at one's own ease, each student has the comfort of going at their own pace. This in turn helps in refining the classroom [10].

As opposed to the traditional classroom, more learning directed in the class lecture is better optimised by doing the lecture under a more comfortable environment [2].Also, instead of being stuck with doubts while doing the assignments at home, the class creates a more humanised atmosphere where the teacher is available to the students [6], can attend to each student personally and target each problem for an individual as opposed to the 'one size fits all' model. This promotes a healthy relation between the student and teacher and also helps create a better understanding of each student individually [4][8][10]. Flipping the class room distributed the workload and the lessened the burden of studies on the students by making creating a complementary environment to other courses. Where classwork becomes homework and homework comes to the class, students wouldn't need personal tutors but the teacher would him/herself be a tutor to each student. Promoting the idea of better concepts and a more concept based learning, the basics would be clear to not only the student, but the teacher too would gain more knowledge on implementing his own knowledge and developing better teaching skills.

\section{The Power of Peer[7] - Computer Programming}

A new approach was tested in Computer Programming course. Some of the students had studied programming in their school and while others had not. This subject was easy for some, interesting to some, and some had an entirely different outlook. It was a challenge for the professor to deliver a one size fits all kind of lecture to all in the class with students having a variance in the level of subject knowledge. Hence a new approach was needed. A student-teacher pair idea was implemented in which each weak student was assigned a partner who was relatively better at the subject. Both students were graded as a pair and not as the individuals. Hence the students who already knew programming mentored all of those who didn't know the subject. They did so, not only to get good grades but also to develop in their partner, an inquisitiveness to learn programming. Peer to peer learning has some advantages over student teacher model. Students are relaxed while learning in this form and can do so with one to one attention. It also helped the students who already knew as it forced them to revise and go through the syllabus once again. Students seem to be more comfortable with someone they can connect to better. The weaker student would get more practice with the ease of the teacher being his own peer. The student is able to target specific problems by pin pointing it out to his peers. The student is also able to connect better to his own peers, even at a personal level. Peers have more discourse that allows a better understanding of the topic [7].

For the students who were more comfortable with $\mathrm{C}$ language, it had learning in teaching approach that made the students practice even more and gave them a better insight to the subject that they already had. The doubts raised by their peers made them help perceive a problem from a different perspective [3]. This gave them not only a new outlook of the problem but also helped in helping their peers understandtheir own way of tackling the problem[9].

From childhood, mostly everyone likes to hear stories; that is one way children develop a sense of auditory learning. By implementing a story telling like approach to understand the many ups and downs faced by several computing related projects and people, each student read and researched about the challenges and lives of people who changed history with their 
work and how innovation was a key to their successes [4]. Each student shared a story which inspired his colleagues and also was a small instance for them to brush up and develop their story telling and oration skills. The audience also learnt the importance of good listening skills as they knew that their peers would only listen to them if they did the same only to realise how important each one of their stories was. Using visual aid, the visual learning was also maximised. This also gave aid to other students as they had the ease of understanding pictorially.

\section{DIY, LIY and HSW - Fundamentals Of Computers}

The terms 'Do It Yourself' (DIY), 'Learn It Yourself' (LIY) and 'How Stuff Works' (HSW)are not merely terms nowadays but is more often with the young generation trying to experiment with new ideas. It is a great way to make the learning experience better by adding academic credits to the work of the students. The course Fundamental of Computers experimented with all three of these in different ways. Each student has a different capability and based on what they are most comfortable with, plays an important role on their understanding of any topic.

Being a course on the knowledge of computer science, web designing is an important aspect of computing, by being instructed with minimum details, the students were given $\mathrm{html}$, data basing projects with DIY approach where each student was allowed to use any resources to create their own website. This resulted in a creative competition among the students as they made websites. It was also very healthy as the student cooperated to help each other in different area of the design [4]. A challenging assignment to make an animation film on a given story using any animation software was given to the students. Surprisingly, no such software was taught by the faculty. The students were given the assignment with the purpose of a LIY outcome where the student must be his own teacher [4]. This helped the student in not only learning about the topic but also seeing how learning and teaching go hand in hand.

Hardware being the most important physical entity of computers couldn't be neglected. On the outside, the CPU of a desktop looks like a box, but when one opens it up is when one realises the beauty of the system embedded into that box. Starting for basic things like different ICs, to ROM and RAM were all showcased to the students. But in the lab, when the entire desktop computer was disassembled and reassembled by the students themselves, gave a puzzle solving like feeling to the students on a more complex platform and was interesting for all. HSW strategy quenched the thirst of the students when theywere able to put things back together in place [1].

The lecture classes as well were made more interactive[4] rather than lecture based as the students were made to participate in different activities which included actualization of several concepts using simple games. Many stories from the field of computing were told that made the subject very interesting. With several projects and more hands on approach in the course, the design capability of the students was tapped. This in turnhelped students in many ways such as to learn to work as a team, handling uncertainties etc. This is shown in detail in Fig.2.

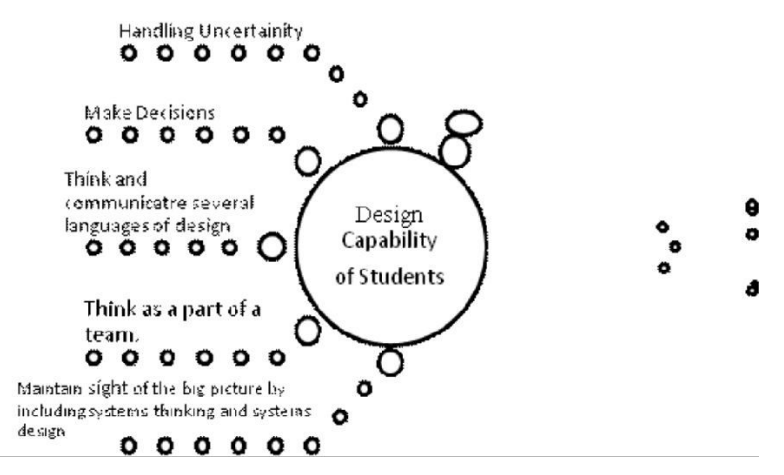

Fig.2. Learnings from Project Based Learning [1].

\section{Conclusions and Outcomes}

Education is not a static process, but rather dynamic in every sense; it cannot have set rules that can be put down. Over time it has come to be seen that education is not something that can follow a one size fits all kind of a model. This paper has discussed a few of the ideologies implemented, that have showing a growth in the learning of students with respect to a change from the classic classroom model. This has been clearly demonstrated through pair programming strategy. To enhance the educational experience, hands on learning plays a major role. This can be achieved through project based approach in various ways, tackled at the scale of individual learners with a greater visible result in the bigger picture of growing and moving forward. The implementation of techniques like DIY, HSW and LIY has given the 
students a perspective of their own to think on how they can optimise their own learning. Storytelling and game playing, while teaching concepts, makes the class very interesting and interactive. Hence, by implementing such pedagogies and experimenting with the educational system, in the beginning it may seem as a big challenge to break out of the traditional system, but over time as the system changes and is more flexible towards change, the teaching learning curve is guaranteed to give an increasing curve.

In conclusion, Table 1 shows how different teaching pedagogies have been implemented at BML Munjal University to form a tailor made teaching style for various courses. This has resulted in effective implementation of knowledge delivery to the students.It has also enhanced the learningand absorbing power of the students, thereby increasing the learning graph.Keeping in mind that each student has a different learning style and it has been observed that there is a relation between teaching pedagogies and different learning styles vieauditory, visual and telekinetic. This is shown in Table 1.

Table 1. Teaching Pedagogies - Effective Implementation

\begin{tabular}{|l|l|l|}
\hline $\begin{array}{l}\text { Teaching } \\
\text { Pedagogy }\end{array}$ & $\begin{array}{l}\text { Effective } \\
\text { Implementation }\end{array}$ & $\begin{array}{l}\text { Learning } \\
\text { Style }\end{array}$ \\
\hline Flip Classroom & Traditional Courses & Visual \\
\hline Peer Evaluation & Innovative Courses & Telekinetic \\
\hline $\begin{array}{l}\text { Presentation } \\
\text { (Story Telling) } \\
\text { (Student) }\end{array}$ & $\begin{array}{l}\text { Application of what } \\
\text { is being taught }\end{array}$ & $\begin{array}{l}\text { Auditory, } \\
\text { Visual }\end{array}$ \\
\hline $\begin{array}{l}\text { Presentation } \\
\text { (Story Telling) } \\
\text { (Teacher) }\end{array}$ & $\begin{array}{l}\text { Evolution of New } \\
\text { Technologies }\end{array}$ & $\begin{array}{l}\text { Auditory, } \\
\text { Visual }\end{array}$ \\
\hline $\begin{array}{l}\text { Project Based } \\
\text { Computing Models }\end{array}$ & $\begin{array}{l}\text { Auditory, } \\
\text { Visual, } \\
\text { Telekinetic }\end{array}$ \\
\hline $\begin{array}{l}\text { Hands on } \\
\text { Learning }\end{array}$ & Workshop Practice & Telekinetic \\
\hline $\begin{array}{l}\text { Do it Yourself } \\
\text { Learn it Yourself } \\
\text { How Stuff } \\
\text { Works }\end{array}$ & $\begin{array}{l}\text { Hardware Based } \\
\text { Courses } \\
\text { Physics } \\
\text { Programming }\end{array}$ & Telekinetic \\
\hline
\end{tabular}

There are still many challenges being faced by the student as well as the teacher.But by implementing newer and innovative teaching pedagogies effectively and also taking into account the learning styles of students, the learning outcomes are definitely going to be optimised.

\section{References}

[1] Clive L. Dym, Alicem. Agogino, Ozgureris, Danield. Frey, Larry J. Leifer, (2005) 'Engineering Design Thinking, Teaching, and Learning', Journal of Engineering Education.

[2] Jeremy F. Strayer (2007), The effects of the classroom flip on the learning environment: A comparison of learning activity in a traditional classroom and a flip classroom that used an intelligent tutoring system.

[3] Viviane M. J. Robinson Claire A. Lloyd Kenneth J. Rowe, (2008), The Impact of Leadership on Student Outcomes: An Analysis of the Differential Effects of Leadership Types', Educational Administration Quarterly, Vol. 44, No. 5.

[4] Michael J. Prince, Richard M. Felder, (2006) 'Inductive Teaching and Learning Methods: Definitions, Comparisons, and Research Bases',Journal of Engineering Education.

[5] Fred A. J. Korthagen, Jos P. A. M. Kessels, (1999) Linking Theory and Practice: Changing the Pedagogy of Teacher Education, Educational Researcher, Vol.28, No. 4, pp. 4-17

[6] Linda Darling-Hammond, (2000) Teacher Quality and Student Achievement: A Review of State Policy Evidence', Education Policy Analysis Archives, Vol 8 No.1

[7] Sima Gupta, (1998) 'Peer evaluation: 'I am not the teacher", ELT Journal Volume 52/1 January 1998 (C) Oxford University Press.

[8] Gwo-Jen Hwang, Judy C.R. Tseng, (2011) 'Development of a ubiquitous learning platform based on a real-time help-seeking platform', British Journal of Educational Technology.

[9] Claire E. Weinstein \& Richard E. Mayer (1983) 'The Teaching of Learning Strategies'National Institute for Staff and Organizational Development.

[10] Salman Khan at TED (2010) https://www. youtube.com/watch?v=nTFEUsudhfs 